\title{
Fichte contra Schopenhauer? A doutrina do Eu como uma fonte teórica do sujeito puro do conhecimento'
}

\author{
Fichte against Schopenhauer? The doctrine of the "Self" as a \\ theoretical source of the pure subject of knowledge
}

\author{
Takao Ito \\ Professor da Universidade de Soka (Japão) \\ Membro da Seção japonesa da Schopenhauer-Gesellschaft \\ E-mail: itotakao@soka.ac.jp \\ Tradução de \\ Jarlee Salviano \\ Professor do Departamento de Filosofia da UFBA \\ Coordenador do GT-Schopenhauer da ANPOF \\ E-mail: jarlee.salviano@ufba.br
}

Resumo: $O$ artigo investiga a possível gênese do conceito schopenhaueriano de "sujeito puro do conhecimento" por meio de uma análise das anotações do jovem Schopenhauer sobre algumas das aulas de Fichte.

Palavras-chave: Schopenhauer; Fichte; Eu; Puro sujeito do conhecimento.
Abstract: The paper investigates the possible genesis of Schopenhauer's concept of "pure subject of knowledge" through an analysis of the notes of the young Schopenhauer about some of Fichte's classes.

Keywords: Schopenhauer; Fichte; Self; Pure subject of knowledge.

\footnotetext{
${ }^{1}$ A tradução do presente artigo recebeu a colaboração de Sidnei Oliveira (UNICAMP).
} 


\section{Introdução}

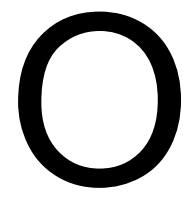
processo de formação da filosofia de Schopenhauer não pode ser suficientemente bem esclarecido se não levarmos em conta a sua relação com Fichte. Cerca de metade do segundo volume da Herança manuscrita (handschriftliche Nachlaß) - que reúne os cadernos de estudos de juventude (426 páginas) com o subtítulo Confrontos Críticos (1809-1918) - traz suas transcrições das aulas de Fichte do semestre de inverno de 1811/1812 na Universidade de Berlim (200 páginas). Essas transcrições são em geral acompanhadas de notas marginais de Schopenhauer, a partir das quais se pode constatar a gênese de alguns de seus conceitos centrais, que mais tarde formarão a base, não só de sua tese de doutorado, mas também de sua obra magna.

A influência de Fichte em Schopenhauer foi tratada outrora principalmente por causa de sua doutrina da Vontade, particularmente por causa de sua doutrina do corpo. Nos últimos anos, contudo, este tema é pesquisado sob um ponto de vista ainda mais abrangente, que abarca também a sua doutrina da Representação, especialmente sua doutrina da intuição. Enquanto há uma tentativa abrangente de tal pesquisa, este ensaio tratará das transcrições de Schopenhauer das aulas de Fichte sobre "o fato da consciência". Além disso, as notas explicativas de Fichte lá presentes devem ser comparadas com as observações acrescentadas por Schopenhauer. Através deste estudo, uma possibilidade deve se apresentar: que também a teoria schopenhaueriana do "sujeito puro do conhecimento" foi construída por ocasião de seu antigo confronto com a filosofia de Fichte. Esta ideia é um dos conceitos básicos da estética de Schopenhauer, por isso ele foi por vezes discutido em conexão com Schelling ou com o romantismo. Embora não se negue isto, parto do princípio de que a origem teórica desse conceito também pode ser encontrada na doutrina do Eu de Fichte.

\section{Princípio de razão}

\subsection{Fundamento}

No primeiro momento de sua aula Sobre os fatos da consciência (Outono de 1811), Fichte caracteriza o "saber científico". Ele afirma que este saber deve Fichte contra Schopenhauer? A doutrina do Eu como uma fonte teórica do sujeito puro do conhecimento 
apresentar o "fundamento das percepções", estabelecendo assim uma lei para todas as percepções possíveis e admitindo que isso pode, portanto, ser determinado a priori para o futuro. "Assim, a ciência eleva-se completamente acima da percepção individual e vai ao fundamento[,] o qual [...] é totalmente separado daquela percepção individual, mais alto, transcendente"². Schopenhauer critica esta caracterização da seguinte forma:

Eu penso a pergunta por que não leva ao fundamento transcendente, mas à relação de um fenômeno com outros. Mas se eu busco, com esta pergunta, o fundamento transcendente, então faço uso transcendente do entendimento de modo indevido (como Kant mostrou $)^{3}$.

A afirmação de Schopenhauer de que o "princípio de razão suficiente" deve ser aplicado apenas à esfera do fenômeno, mais tarde torna-se um importante tema de sua tese Sobre a quádrupla raiz do princípio de razão suficiente (1813). No entanto, não se pode simplesmente concluir que o uso de Fichte da palavra "Fundamento" é transcendente. Pois o uso de Fitche difere do de Schopenhauer, embora para ambos a palavra "Fundamento" signifique condições de possibilidade das percepções. Com esta palavra, Fichte pensa em condições da parte percipiente (wahrnehmenden), enquanto Schopenhauer se refere à parte percebida (wahrgenomenden). Dito kantianamente, no primeiro caso é mostrado um fundamento transcendental, que precede e possibilita a percepção. No segundo caso, no entanto, é exposto um fundamento empírico, que é a causa de todo estado na esfera de percepção.

\subsection{Região dos fundamentos}

Sem tomar conhecimento destas distinções de significado, Schopenhauer eleva sempre mais sua crítica contra Fichte. No segundo momento da aula acima mencionada, Fichte fala da esfera da ciência, isto é, a "Região dos fundamentos" enquanto transcendente.

Todos nós nascemos nesse mundo das percepções, não na ciência, que deve ser adquirida, e cada um deve adquiri-la por si mesmo: isto

2 SCHOPENHAUER, A. HN, 2, p. 19.

3 Idem, p. 21.

Fichte contra Schopenhauer? A doutrina do Eu como uma fonte teórica do sujeito puro do conhecimento 
é, deve ultrapassar com suas próprias forças aquele mundo da mistura caótica dos fenômenos, na direção dos fundamentos transcendentes $[\ldots]^{4}$.

Para esta afirmação Schopenhauer dá o seguinte parecer:

Considero em geral todo o saber dentro dos limites da experiência como condicionado sensivelmente e válido apenas na experiência, como nulo mesmo, pois é sempre condicionado (a Matemática inclusive) pelos limites da experiência. Tomo-o como um erro, precisamente porque a realidade da experiência é erro, para cada "por causa disto" permanece de pé um novo "por que" na experiência, e toda a nossa verdade é sempre apenas um erro $[\ldots]^{5}$.

Embora ambos os filósofos considerem o mundo das percepções como inferior e relativo, suas respectivas justificativas para isto se confrontam. Fichte relativiza esse mundo porque não é a região dos fundamentos. No entanto, Schopenhauer relativiza o mundo da experiência precisamente porque é a região dos fundamentos. Esta oposição vem do uso diferenciado da palavra "Fundamento". O comentário de Schopenhauer acima citado reflete as seguintes palavras de sua tese: "toda dependência, relatividade, instabilidade e finitude dos objetos para nossa sensibilidade, ententimento e razão, sujeito e objeto perturbam a consciência [...]"6.

\subsection{Percepção da percepção}

Desta distinção de significado de palavra surge a conhecida crítica schopenhaueriana a Fichte, na qual ele se opôs ao uso de Fichte do princípio de razão no sujeito na doutrina do Eu. No início de sua nova tríade de aulas Sobre os fatos da consciência e a Doutrina-da-ciência (Inverno 1811-1812), Fichte afirma que não lida com a pura observação da "percepção da percepção". "O Factum dado é o próprio mundo exterior e é acessível a todos porque exige somente os sentidos externos. No entanto, a percepção da percepção ocorre mesmo por um sentido interno: a quem isso não é acessível, para ele não há filosofia”. A esta ideia Schopenhauer comentou o seguinte:

4 SCHOPENHAUER, A. HN, 2, p. 21. 
O ponto de absoluta clareza de consciência que deve guiá-los [os ouvintes] para Fichte é, como me parece, o único existente que por si não depende da percepção e não é consciência dada através dela, da qual emerge o espanto filosófico sobre o mundo, ou seja, sobre aquela segunda consciência na percepção (que é o senso comum, o único). Este espanto faz o filósofo e o filósofo é um ser humano, o que procura unir aquelas duas consciências completamente diferentes. $O$ fracasso consiste em que alguns negam o que não é dado pela consciência através da percepção, eles são chamados realistas e materialistas; e outros, então, que negam na percepção o dado da consciência: são idealistas ${ }^{8}$.

Também esta asserção é incluída em sua tese. Lá, Schopenhauer explicou que o realismo e o idealismo cometem o mesmo erro, porque ela, a causalidade, isto é, uma espécie de princípio de razão, se aplica ao sujeito. Segundo o realismo, a representação surge através de uma causalidade do objeto: o sujeito está sujeito, por conseguinte, à lei de causalidade passiva. Em consequência, o idealismo surge na representação, todavia, através de uma causalidade do sujeito; este é, no entanto, ativo à lei de causalidade 9 . Com base nisso, Schopenhauer critica a doutrina de Fichte do Eu:

Não melhoramos nada, desse modo, colocando no lugar do sujeito o eu absoluto. Então aqui está principalmente esse sujeito, por isso ele não pode ficar sob as leis que se aplicam a certas classes de objetos, porque antes de tudo, como o sujeito e único para o sujeito objeto lá estão ${ }^{10}$.

Levando em consideração o significado diverso da palavra, não deixa imaginar-se, portanto, a crítica de Schopenhauer a Fichte, porque a relação entre o eu e o mundo em Fichte nem sempre é subsumida pelo conceito de "causalidade" schopenhaueriana.

Realmente, a diferença sobre o princípio de razão entre os dois filósofos está ficando maior, a aula mais distante na direção do "poder prático do eu" progride, o que examinaremos a seguir.

\section{Doutrina da vontade}

8 SCHOPENHAUER, A. HN, 2, p. 30.

9 SCHOPENHAUER, A. SW, 7, p. 44.

10 SCHOPENHAUER, A. SW, 7, p. 45.

Fichte contra Schopenhauer? A doutrina do Eu como uma fonte teórica do sujeito puro do conhecimento 


\subsection{Determinação}

Na primeira hora da segunda parte de sua aula sobre os fatos da consciência e a doutrina da ciência, Fichte trata a "autodeterminação do eu", isto é, a transição do eu de uma determinação para o oposto. Além disso, para Fichte o eu é apenas uma prática, se ele não é percebido apenas como passivo reproduzido, mas também o próprio ativo na percepção intervém. Para passar do passivo para o ativo, o próprio eu deve ser determinado. Esta definição (Bestimmung) chama-se "determinação" (Entschluß). "Ele é um golpe, um raio, intemporal. Em qual tempo ele deveria ser? No fluxo do tempo a reprodução não é: no fluxo do tempo a percepção também não"11. Para esse esclarecimento, Schopenhauer diz o seguinte: "Que a determinação está fora de todo o tempo, se permite dizer nesse ponto, que ele é um ato da vontade, como uma coisa em si sobre todo o tempo"12.

Deste comentário Schopenhauer desenvolveu a sua doutrina da Vontade. Em sua tese se lê: "Uma determinação mais serena [depende] apenas do próprio sujeito imediato do querer: deste, contudo, do sujeito do querer, é perceptível apenas o querer mesmo, não o querer do estado anterior" ${ }^{13}$. Embora se possa esclarecer toda determinação com qualquer querer que o precede, não se pode mostrar outro fundamento para isto, que aquele querer que se quis. Este estado de volição anterior não é, de fato, "objeto do sentido interno, nem nada no tempo"14. Dito kantianamente, Schopenhauer descreve aqui o sujeito do querer em dois níveis diferentes: isto é, em primeiro lugar, no plano empírico, que está subordinado, como fenômeno, à lei da causalidade, e, em segundo lugar, no plano transcendental, o qual, como condição de possibilidade da experiência, é livre desta. Tanto para Fichte quanto para Schopenhauer, portanto, a determinação representa um ato da vontade, que é livre da temporalidade. A diferença está em considerar se indicamos a "Vontade" como "Fundamento" ou não.

\subsection{Princípio}

No mesmo momento da aula, Fichte investiga ainda a auto-determinação do

11 SCHOPENHAUER, HN 2, p. 56.

12 Idem, p. 57.

13 SCHOPENHAUER, A. SW, 7, p. 74

$14 \mathrm{ldem}$, p. 76.

Fichte contra Schopenhauer? A doutrina do Eu como uma fonte teórica do sujeito puro do conhecimento 
Eu. Ele diz que tudo o que é determinado pelo Eu é "fático", ou seja, físico. Por conseguinte, o próprio Eu como um "princípio" do mesmo deve ser "suprafático", ou seja, metafísico. No entanto, deve "este ser suprafático [...] seria um ser determinado; não só porque deve ser uma lei e, portanto, não é permitido ser indeterminado e aleatório, mas também porque nosso pensamento segue o princípio de razão" ${ }^{15}$. Contra essas sanções levanta Schopenhauer a seguinte objeção:

Ele [Fichte] quer idealismo! Que ele o quer é resultado de suas incompreensões individuais da doutrina de Kant, e talvez isto seja novamente causado por uma incompletude na doutrina de Kant. Então, ele quer que o Princípio do Eu (ele não diz a "causa" porque Kant bane o termo como imanente na metafísica propriamente, mas o uso da palavra "princípio" é uma capa de chuva de papel, e não mostra quais fracas defesas Fichte não desdenhava) seja todas as suas representações, ou seja, todo o mundo da experiência ${ }^{16}$.

A diferença entre os dois filósofos pode ser formulada da seguinte forma: segundo Fichte, o Eu é um transcendental que determina como princípio todo empírico. Além disso, também deve ser determinada metafisicamente a relação entre um transcendental e todo empírico pelo "princípio de razão" (Assim, Fichte expressa essa relação também através do par de conceitos "princípio e principiado" [Principiat]). Schopenhauer, no entanto, equipara o conceito de Fichte "princípio" com o termo "causa".

Assim, ele critica a filosofia de Fichte como idealismo, que do Eu faz surgir todo o mundo da experiência. Também em sua tese, Schopenhauer censura esse par de conceitos "princípio e principiado" por seu uso de modo obscuro e transcendente ${ }^{17}$.

\section{$2.3 \mathrm{OEu}$}

Logo após a introdução do conceito "princípio", Fichte apresenta sua estrutura teórica da determinação. Segundo Fichte, a determinaçao é

uma ruptura fática do ser determinante, o qual deve ser antes inibido:

15 SCHOPENHAUER, A. HN, 2, p. 57.

16 Idem, 7, p. 92.

17 Cf. SCHOPENHAUER, A. SW, 7, p. 92.

Fichte contra Schopenhauer? A doutrina do Eu como uma fonte teórica do sujeito puro do conhecimento 
durante esta inibição mostra-se, pois, como sentimento um impulso e como este é incorporado nos fatos da consciência. Abstraímos do Eu todo ser fático, o que faz restar um impulso, princípio do Ser. Esse impulso não é o ser suprafático (überfaktische), uma vez que não vem a ser, nem no tempo, mas pode ocorrer para este impulso, onde se revela ${ }^{18}$.

A esta declaração Schopenhauer comenta:

Deve pois a alma (nobre Eu, ou também Saber, ou mesmo o chamado Ser, depois eles aparecem mais ou menos in pontificalibus, como se não reconhecesse o já demonstrado paralogismo da razão pura de Kant), de acordo com o paralogismo da razão pura, completamente una, inalterável, incapaz de qualquer modificação, ser plenamente suficiente: mas vemos que o mundo, seu princípio (ao invés de efeito), mesmo diverso, é mutável e uma coisa tola. Para explicar isso, ele dá à alma um impulso, que é mesmo tão tolo que sempre quer alguma coisa, e, quando a tem, quer novamente outra coisa; e assim postula o mundo em movimento ${ }^{19}$.

Também aqui os dois filósofos falam um ao outro sem se entender. Fichte chama a determinação de ruptura fática do Eu suprafático. No entanto, nesta definição Schopenhauer denuncia uma contradição interna que faz com que a louca multiplicidade mutável advenha do imutável e perfeito Uno. Em sua tese, a explicação de Schopenhauer da "determinação" não está muito longe da explicação de Fichte. Schopenhauer apresenta a determinação como "um ato da vontade universal estendido fora do tempo[...], da qual todo ato efetivado no tempo é apenas o surgimento do fenômeno". Ele explicou a relação entre o ato de vontade universal e tudo o que ocorre no tempo com o par de conceitos kantiano (e schellinguiano) "caráter inteligível" e "caráter empírico"20. Portanto, tanto Fichte quanto Schopenhauer procuraram o Eu não só no aspecto empírico, mas também apresentam o aspecto transcendental.

Portanto, pode-se aqui obervar uma espécie de paralelismo teórico entre a doutrina do Eu de Fichte e a doutrina da Vontade de Schopenhauer, a despeito de sua diferença em relação ao princípio de razão suficiente acima mencionado.

\section{Doutrina da representação}

18 SCHOPENHAUER, A. HN, 2, p. 58

19 Idem, p. 60.

20 SCHOPENHAUER, A. SW, 7, p. 76.

Fichte contra Schopenhauer? A doutrina do Eu como uma fonte teórica do sujeito puro do conhecimento 


\subsection{Inteligir do Eu}

A partir do quarto momento da segunda parte da sua aula acima mencionada, Fichte começa "um inteligir do Eu", ou seja, apresentar um pensamento puro como a última condição de autodeterminação. A princípio, Fichte apresenta uma definição renovada do $\mathrm{Eu}$, que é "uma intuição absolutamente imediata dos intuintes (Anschauenden) e dos intuídos (Angeschauten)". Em seguida, afirma: "uma intuição imediata; ou seja, essa identidade não é algo concluído ou fechado, mas é dada pelo saber e o olhar imediato: elas são de fato ligadas: a identidade é afirmada no crédito da intuição sem outro fundamento" ${ }^{21}$. Nesta definição do Eu, Schopenhauer lança apenas uma rápida crítica: "Há apenas um Intuinte, o Eu: e este nunca é de fato um intuído"22.

Esta crítica a Fichte é formulada mais tarde por Schopenhauer em sua tese do seguinte modo: "Objeto é tudo que é conhecido, sujeito é o cognoscente e, por isso mesmo, enquanto ele conhece, nunca é conhecido"23. A própria perspectiva de Schopehauer é, talvez, mais próxima da de Fichte do que Schopenhauer imagina. Ele afirma que o sujeito só pode ser conhecido como "um querente, uma espontaneidade", mas não como um "conhecedor" 24 . Embora a palavra "Eu" se refira a estes dois aspectos, "a identidade do sujeito do querer com o sujeito cognoscente" é "absolutamente incompreensível", pois para o sujeito cognoscente as regras para o conhecimento de objetos [ou seja, as formas do princípio de razão] não se aplicam mais e "uma identidade real do cognoscente com a coisa conhecida enquanto querente, portanto do sujeito com o objeto" é "imediatamente dada" ${ }^{25}$. Considerandose este esclarecimento, não se pode negar que mesmo Schopenhauer reconhece uma espécie de intuição de si, mas ela não é chamada "intuição".

\subsection{Intuição superior}

21 SCHOPENHAUER, A. HN, 2, p. 68. 22 Idem, ibidem. 
No oitavo momento das aulas de Fichte, ele leva adiante sua teoria da "intuição superior", a qual aparece diante do Eu fático [ou seja, o Eu empírico] como "uma lei absoluta de suas ações, um Deve". Ele afirma que esta intuição em si é "a imagem imediata do Ser absoluto" e seu princípio "o próprio absoluto". "O Eu fático é também, de certo ponto de vista, um princípio desta intuição, mas somente por arrancar os impulsos é fundamento, que para ela [ou seja, para a imagem imediata do absoluto Ser] ocasiona essa intuição, mas não que ele pode aparecer em tudo, e é"26. Com a expressão anterior do quarto momento mencionado, o Eu só é fático desde que tenha uma intuição de sua identidade com qualquer impulso. Esse ponto de vista, no entanto, Schopenhauer questiona: "Como se pode chegar ao Eu, libertar-se dos impulsos, se já não se tem antes esta intuição? Além disso, ela revela-se também aos próprios impulsos e se entrega como uma consciência cautelar"27.

Resumidamente, Schopenhauer argumenta contra Fichte que a intuição mais elevada permite romper com o impulso, mas não o contrário. Esta afirmação provavelmente reflete-se mais tarde na seguinte frase de sua tese: "O motivo tem sempre a decisão de antemão"28. No entanto, essa crítica é inadequada, pois Fichte nem sempre trata a relação entre a "libertação do impulso" e a "intuição mais elevada" como causalidade temporal. Em vez disso, uma espécie de parentesco com Fichte pode ser observada na posterior teoria da virtude de Schopenhauer. Em 1811, Schopenhauer escreve: "Quanto mais superior o ser humano se avalia como homo noumenon, menor ele é em si mesmo como homo phaenomenon ou sobre qualquer preferência que ele tenha, como tal, em colocar um valor" ${ }^{29}$. No fragmento n. 66 (de 1813), ele também diz: "Mas o poder do próprio Eu (como temporal e espacial, bem como não-temporal e não-espacial) de se tornar consciente (colocarse) é a liberdade"30. Dito com as palavras de Fichte, é necessário para a virtude que o Eu seja consciente não do seu lado fático, mas do seu lado suprafático.

\subsection{Fundamento inteligível}

26 SCHOPENHAUER, A. HN, 2, p. 79. 
Antes que Schopenhauer reconheça essa semelhança com Fichte, segue-se a segunda parte da aula de Fichte até o fim. Nela Fichte resume seu pensamento sobre o Eu. A forma em que o Eu tem a "intuição superior", ou seja, vê a si mesmo como "uma imagem do Ser absoluto" alcançado pela libertação dos impulsos, é o fundamento de todo o saber fático. O próprio Eu é, no entanto, compreendido exclusivamente como o "fundamento inteligível", que é contraposto a todos os indivíduos fáticos ${ }^{31}$. Fichte diz: "Aquele Uno puro Eu, o Eu-forma, nunca está na realidade, ele contradiz a lei da realidade [...]. Pode, portanto, ao pensamento que nós efetuamos, nunca ser dado na intuição um correspondente: ele é, portanto, puramente inteligido" ${ }^{32}$. Schopenhauer comentou ironicamente essa afirmação: "Exatamente como a Quimera é o puramente inteligido, o Centauro e Satanás"33.

Para Schopenhauer, o conceito de Fichte do não intuinte, mas apenas pensante puro Eu talvez seja semelhante a um ente mítico. Esta crítica a Fichte é formulada mais tarde na tese de Schopenhauer com rebuscada expressão. "O Eu representante, o sujeito do conhecimento, nunca pode ser representação ou objeto (pois ele, enquanto correlato necessário de todas as representações, é condição desta)"34. Esta é a primeira demonstração pública de sua teoria da representação. Mas esta frase somente não é com exatidão uma prova da distinção de pensamento entre os dois filósofos. Em seguida, afirma Schopenhauer:

\footnotetext{
A frase: "Eu conheço", é, contudo, analítica, porque o conhecimento é inseparável do Eu, ou seja, do sujeito do conhecimento e do juízo, e é sempre com ele um predicado já definido. Ou seja, o sujeito daquela proposição analítica não é constituído por Síntese, mas originalmente no sentido mais estrito, dado como uma condição de todas as representações ${ }^{35}$.
}

Por outro lado, "'eu quero' é uma frase sintética, e mesmo a posteriori, através da experiência, neste caso experiência interna (isto é, somente no tempo)"36. Não é perceptível aqui nenhum parentesco com o par de conceitos "puro Eu" e "fático Eu" de Fichte? Não se pode sequer constatar naquele contraste entre o "eu conheço" e o

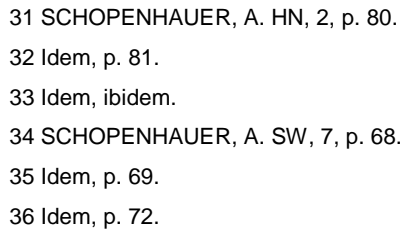


"eu quero" um arquétipo do posterior contraste feito por Schopenhauer entre o "Sujeito puro do conhecimento, isento de vontade" e o "indivíduo único mutável"

Parece ser possível que, mesmo aqui, uma direção comum de pensamento entre Fichte e Schopenhauer pode ser encontrada: a duplicidade da consciência de si coloca-se no centro de sua investigação.

\section{Conclusão}

Considerando as transcrições de Schopenhauer da série de aulas de Fichte sobre "O fato da consciência", pode-se, então, supor que as doutrinas schopenhauerianas da Vontade e da Representação, de sua obra posterior, configuram propriamente uma antítese contra Fichte. No entanto, Schopenhauer preferiu neste momento julgar unilateralmente a filosofia de Fichte como um idealismo, segundo o qual o Eu origina todo o mundo da experiência. Este engano surge devido à equiparação de Schopenhauer do conceito transcendental de Fichte "fundamento" com o conceito empírico "causa".

Por outro lado, o próprio Schopenhauer define o Eu como "a identidade do sujeito do querer com o sujeito cognoscente" e menciona uma possibilidade de dominação daquele sujeito em relação ao segundo sujeito, em outras palavras, do sujeito como homo phaenomenon e o sujeito como homo noumenon. Aqui se pode perceber não só uma gênese de seu conceito de "sujeito puro do conhecimento", mas também uma semelhança teórica com a ideia de Fichte de "libertação do impulso" ou a "intuição superior". Resumidamente, Schopenhauer vislumbrou na filosofia de Fichte um "uso transcendente" do entendimento. Ao criticar, contudo, o incompreendido pensamento de Fichte, ele se aproximou dele de forma involuntária, em especial da doutrina do Eu. Podemos, portanto, dizer que, no desenvolvimento da filosofia juvenil de Schopenhauer, o pensamento de Fichte esteve envolvido, por assim dizer, como uma catálise.

37 Idem, p. 207-212. 


\section{Referências bibliográficas}

SCHOPENHAUER, Arthur. Sämtliche Werke. Hrsg. von Arthur Hübscher. 7 Bde. Wiesbaden: F. A.Brockhaus, 1972.

Der Handschriftliche Nachlaß. Hrsg. von Arthur Hübscher. 5 Bde. Frankfurt am Main: Verlag Waldemar Kramer, 1966-1975. 1997.

Schopenhauer's Early Fourfold Root. Transl. by F. C. White, Aldershot: Avebury,

. Manuscript Remains. Edit. by Arthur Hübsche: Transl. by E. F. J. Payne. 4vols. Oxford: Berg, 1988.

KANT, Immanuel. Kants gesammelte Schriften. Hrsg. von der Königlich Preußischen Akademie der Wissenschaften. Berlin: Druck und Verlag von Georg Reimer, 1900ff.

FICHTE, Johann Gottlieb. Fichtes Werke. Hrsg. v. I. H. Fichte. 11Bde. Berlin: Walter de Gruyter, 1971.

Recebido: 03/12/15

Received: 12/03/15

Aprovado: 20/12/15

Approved: 12/20/15 